\title{
Spotlight on necitumumab in the treatment of non-small-cell lung carcinoma
}

\author{
This article was published in the following Dove Press journal: \\ Lung Cancer:Targets and Therapy \\ 13 February 2017 \\ Number of times this article has been viewed
}

\author{
Manish K Thakur \\ Antoinette J Wozniak \\ Department of Oncology, Karmanos \\ Cancer Center, Detroit, MI, USA
}

Correspondence: Antoinette J Wozniak Department of Oncology, Karmanos Cancer Center, 4100 John R, Detroit, MI 4820I, USA

Email wozniakt@karmanos.org

\begin{abstract}
The treatment options for metastatic non-small-cell lung cancer (NSCLC) have expanded dramatically in the last 10 years with the discovery of newer drugs and targeted therapy. Epidermal growth factor receptor (EGFR), when aberrantly activated, promotes cell growth and contributes in various ways to the malignant process. EGFR has become an important therapeutic target in a variety of malignancies. Small-molecule tyrosine kinase inhibitors (TKIs) of EGFR are being used to treat advanced NSCLC and are particularly effective in the presence of EGFR mutations. Monoclonal antibodies have also been developed that block the EGFR at the cell surface and work in conjunction with chemotherapy. Necitumumab is a second-generation fully human IgG1 monoclonal antibody that has shown promise in metastatic NSCLC. The benefit has mostly been restricted to squamous cell lung cancer in the frontline setting. Considering that the survival advantage for these patients was modest, there is a need to discover biomarkers that will predict which patients will likely have the best outcomes. This review focuses on the development and clinical trial experience with necitumumab in NSCLC.
\end{abstract}

Keywords: lung cancer, squamous cell, necitumumab, EGFR

\section{Introduction}

Lung cancer is one of the most common causes of cancer-related mortality with $>160,000$ deaths annually in the US. ${ }^{1}$ Non-small-cell lung cancer (NSCLC) represents $\sim 80 \%-85 \%$ of all lung cancers. ${ }^{2}$ Within the NSCLC category, adenocarcinoma accounts for $40 \%$ of the cases, squamous cell histology for $25 \%-30 \%$ and large cell carcinoma for $10 \%-15 \%{ }^{3}$ NSCLC is usually diagnosed as locally advanced or metastatic in $\sim 70 \%$ of the patients. ${ }^{4}$ The standard first-line treatment in this group of patients has historically been chemotherapy, preferably with a platinum doublet. ${ }^{5}$ With the discovery of actionable molecular abnormalities, such as epidermal growth factor receptor (EGFR) mutations and EML4-ALK and ROS1 rearrangements, the treatment paradigm has changed dramatically and agents inhibiting these targets are being used for initial treatment. ${ }^{6}$ More recently, immunotherapy with PD1/PD-L1 inhibitors has been approved as the first-line treatment. ${ }^{7}$ Immunotherapy is also approved as the firstline therapy if PD-L1 expression is present in at least $50 \%$ of the cells. ${ }^{7}$ Squamous cell lung cancer has a high mutational burden, with molecular analyses showing the presence of aberrations in PI3KA, AKT, and FGFRI among others. ${ }^{8-10}$ Currently, there are no available therapies for these molecular abnormalities, and the presence of actionable mutations is found more infrequently when compared to patients with adenocarcinoma histology (ie, $E G F R, A L K$, and ROS1). This makes chemotherapy the only treatment option available for use in most squamous cell lung cancer patients. ${ }^{11}$ 


\section{Epidermal growth factor}

EGFR has been a therapeutic target via small-molecule tyrosine kinase inhibitors (TKIs) that are particularly effective in the presence of EGFR-activating mutations or by blocking EGFR signaling with antibodies that bind to the cell surface. ${ }^{12,13}$ EGFR belongs to the ERBB family of transmembrane receptors, which also includes Her2/Neu, ERBB3, and ERBB4. ${ }^{14}$ These are receptor tyrosine kinases that are present on the cell surface and bind to ligands such as EGF and TNF $\alpha$ that cause receptor dimerization and downstream signaling. The MAPK and PI3/AKT pathways are the intracellular pathways activated by this signaling. The consequences are cell differentiation, proliferation, decreased apoptosis, and increased metastatic potential. ${ }^{15}$ The strategy of blocking EGFR with monoclonal antibodies potentially results in the formation of an antibody receptor complex with internalization and degradation. Another proposed mechanism of action associated with these antibodies is antibody-dependent cellular cytotoxicity (ADCC) and complement-mediated cytotoxicity. ${ }^{16}$ Various monoclonal antibodies have been studied in advanced NSCLC, including cetuximab, panitumumab, and necitumumab.

\section{Cetuximab}

Cetuximab belongs to the IgG1 class of antibody that is chimeric human and murine in nature. The $\mathrm{Fc}$ portion of this antibody is capable of inducing ADCC. ${ }^{16}$ Cetuximab showed promising results in two Phase II trials in NSCLC. ${ }^{17,18}$ Both of these studies used a platinum doublet (platin plus vinorelbine or gemcitabine) in combination with cetuximab. The triplet therapy was well tolerated that led to Phase III trials. The FLEX trial was a randomized, open-label Phase III study that compared cetuximab in combination with cisplatin and vinorelbine with chemotherapy alone in advanced NSCLC that expressed EGFR.$^{19}$ The primary end point of this trial was overall survival (OS). EGFR was assessed using immunohistochemistry, and at least $1 \%$ of tumor cells had to be positive as an eligibility requirement. Chemotherapy was given for six cycles, but cetuximab continued until disease progression or toxicity. The median OS was noted to be 11.3 months in the cetuximab arm vs 10.1 months in the control arm (hazard ration [HR] $=0.871,95 \%$ confidence interval $[\mathrm{CI}]: 0.762-0.996, P=0.44$ ) for all histologies. For squamous cell pathology specifically, survival benefit was 10.2 months (8.2-12.0 months) in the cetuximab arm as compared to 8.9 months (6.9-10.2 months) in the chemotherapy arm. BMS 099 was the second Phase III trial that compared cetuximab in combination with carboplatin and paclitaxel or docetaxel with chemotherapy alone. ${ }^{20}$ In this study, progression-free survival (PFS) was the primary end point with OS being a secondary objective. The median PFS was comparable in both arms, 4.40 months in the experimental arm vs 4.24 in the control (HR $=0.902,95 \%$ CI: $0.761-1.069$, $P=0.236$ ). These results were similar to the PFS in the FLEX trial. However, the median OS was 9.69 months in the cetuximab arm vs 8.38 months in the control arm, which was not significant (HR $=0.89,95 \% \mathrm{CI}: 0.754-1.051, P=0.169)$. The response rates were higher in both these trials in the cetuximab arm (Table 1). Subsequently, a meta-analysis was published that confirmed the improvement in OS and RR with the addition of cetuximab to chemotherapy. ${ }^{21}$ Due to the very modest survival advantage for cetuximab in the FLEX trial, it was never approved for use in the treatment of NSCLC.

\section{Necitumumab}

Necitumumab or IMC-11F8 is a recombinant IgG1 antiEGFR antibody that is fully humanized. ${ }^{22}$ Compared to cetuximab, it lacks the murine component, subsequently resulting in fewer hypersensitivity reactions. IMC-11F8 was found to have a high affinity for EGFR in A431 epidermoid cell lines with growth inhibition in human tumor xenografts. ${ }^{23,24}$ Necitumumab was found to bind EGFR with an affinity of $0.28 \mathrm{nM}$ and was able to block receptor phosphorylation and MAPK pathway activation in several tumor cell lines. ${ }^{25}$ A subsequent study investigated its chemical structure and found the drug to act on similar epitopes as cetuximab through a different set of interactions. ${ }^{22}$ It has been shown that necitumumab binds to domain III of the extracellular region of EGFR, thus blocking the ligand-binding site. This leads to a change in configuration that prevents dimerization and downstream signaling of the EGFR receptor. ${ }^{22}$

Table I Phase III trials comparing cetuximab with chemotherapy in advanced NSCLC

\begin{tabular}{lllllll}
\hline Trial & Treatment & $\mathbf{n}$ & RR (\%) & PFS (months) & OS (months) & HR (95\% CI) \\
\hline FLEX'19 & Ci/V & 568 & 29 & 4.8 & 10.1 & $0.87(0.76-0.99)$ \\
& $\mathrm{Ci} / \mathrm{V} / \mathrm{Ctx}$ & 557 & 36 & 4.8 & 11.3 & \\
\multirow{2}{*}{ BMS 09920 } & $\mathrm{Ca} / \mathrm{T}$ & 338 & 17 & 4.4 & 8.4 & $0.89(0.75-1.05)$ \\
& $\mathrm{Ca} / \mathrm{T} / \mathrm{Ctx}$ & 338 & 26 & 4.2 & 9.7 & \\
\hline
\end{tabular}

Abbreviations: $\mathrm{Ca}$, carboplatin; $\mathrm{Ci}$, cisplatin; $\mathrm{Ctx}$, cetuximab; NSCLC, non-small-cell lung cancer; OS, overall survival; PFS, progression-free survival; T, docetaxel/paclitaxel; $\mathrm{V}$, vinoralbine; $\mathrm{Cl}$, confidence interval. 


\section{Preclinical data}

Necitumumab was initially tested in vitro with cell lines from tumors, including epidermis, pancreas, and colorectal, that showed overexpression of EGFR. It had an inhibitory effect in all these tumor lines. ${ }^{25}$ When tested in NSCLC cell lines, necitumumab showed rapid degradation as well as internalization of the EGFR. ${ }^{26}$ Being an IgG1 subclass, necitumumab was able to induce ADCC in NSCLC cells and this correlated with the level of EGFR expression on the cell lines. ${ }^{27} \mathrm{ADCC}$ was induced at levels as low as $1.0 \mathrm{nM}$, and the results were comparable to that produced by cetuximab. Necitumumab was tested in mice in combination with chemotherapy. ${ }^{28}$ It was administered with cisplatin and gemcitabine after establishing maximum tolerated dose in athymic mice. Using two human NSCLC cells, A549 and NCI-H1650, partial tumor regression was seen in $33 \%$ and $58 \%$, respectively, when chemotherapy was combined with IMC-11F8. Necitumumab was also studied in combination with cisplatin plus gemcitabine, pemetrexed, or paclitaxel in preclinical models. ${ }^{29}$ The combination with cisplatin and gemcitabine was found to be the most effective. An association with regard to efficacy was noted with the presence of an increased expression of hsa-miR-29b and a decreased expression of antiapoptotic genes, such as DNA methyltransferase $D N M T 3 B$. These abnormalities are often seen in patients with NSCLC.

\section{Phase I trials}

The first Phase I trial with necitumumab enrolled 60 patients into two study arms: Arm A received treatment once weekly and Arm B received treatment every 2 weeks. ${ }^{30}$ The patients had solid malignancies in advanced stage who had not received any prior EGFR-directed treatment. The range of necitumumab doses was $100-1000 \mathrm{mg}$. A total of 57 patients were evaluable, and $55(91.7 \%)$ patients discontinued treatment due to disease progression. The most common drug-related adverse events involved the skin and were experienced by $80 \%$ of the patients, which included acneform rash, skin dryness, and fissure formation, most of which were mild (grade 1) in severity and cumulative. Two patients had grade 3 acneform rash. A total of $42 \%$ of the patients experienced headaches, $20 \%$ experienced vomiting, and $33 \%$ of them experienced nausea, which were all grade 1 . No hypersensitivity reactions were observed. Overall, the drug was tolerated well and a flat weekly or Q2 week dose of $800 \mathrm{mg}$ was recommended.

A subsequent Japanese trial enrolled patients using a $3+3$ design with dosing schedules of cohort 1: $600 \mathrm{mg}$ on days 1 and 8 , every 3 weeks; cohort 2: $800 \mathrm{mg}$ on day 1 , every 2 weeks; and cohort 3: $800 \mathrm{mg}$ on days 1 and 8, every 3 weeks. ${ }^{31}$ Fourteen patients were evaluable. The most common side effect was headache in $66 \%$ of the patients with rash in $53.3 \%$ of them. All side effects were grade $1 / 2$. A disease control rate of $67 \%$ was achieved in this study. No doselimiting toxicity was observed, and the maximum tolerated dose was not reached. The highest dose level corresponded with Phase I trial by Kuenen et al. ${ }^{30}$

\section{Phase II trials}

A Phase II trial was conducted by Elez et a $l^{32}$ that combined necitumumab with modified FOLFOX6. This involved 44 patients with locally advanced or metastatic colorectal cancer. Nectumumab was given at $800 \mathrm{mg}$ intravenous every 2 weeks along with chemotherapy. The primary end point was PFS. An objective response rate of $63 \%$ was observed with a median duration of 10 months (range: 7-16 months). These included four complete responses. The PFS was 10 months (range: 7-12 months), and the OS was 22.5 months (range: 11-30 months). Eighty-six percent of the patients had grade 3 or higher events with most common being neutropenia, asthenia, and rash. Forty-one patients (93.2\%) experienced some form of skin toxicity of any grade. Overall, the study showed a manageable toxicity profile in this population.

A Phase II trial evaluating necitumumab combined with cisplatin and gemcitabine in stage 4 squamous cell lung cancer patients was completed, but results are currently not available (NCT01606748). This was an open-label trial that investigated the pharmacokinetics of the drug in combination with chemotherapy. Another trial with the same combination is evaluating the safety in this population (NCT01788566).

A randomized Phase II trial is studying carboplatin and paclitaxel \pm necitumumab (NCT01769391) as the first-line therapy for patients with metastatic squamous cell lung cancer. An additional Phase II trial is testing nab-paclitaxel and carboplatin combined with necitumumab (NCT02392507). Interestingly, both nab-paclitaxel and necitumumab are continued as maintenance after the completion of four cycles of the triplet therapy with carboplatin. Since the resistance mechanism for necitumumab is unclear, combining it with chemotherapy in maintenance phase could potentially prolong the benefit. Another trial is testing LY3023414 with necitumumab (NCT02443337) in metastatic squamous cell lung cancers.

\section{Phase III trials}

There have been two Phase III trials (Table 2) that have evaluated necitumumab in NSCLC. The INSPIRE trial enrolled 
Table 2 Comparison of Phase III trials with necitumumab in NSCLC

\begin{tabular}{|c|c|c|c|c|}
\hline$\overline{\text { Trial }}$ & INSPIRE $^{34}$ & & SQUIRE $^{33}$ & \\
\hline Patients (n) & 633 & & 1093 & \\
\hline Histology & Nonsquamous & & Squamous & \\
\hline Treatment $(\mathrm{n})$ & $\mathrm{C} / \mathrm{P} / \mathrm{N}(315)$ & $C / P(3 \mid 8)$ & $\mathrm{C} / \mathrm{G} / \mathrm{N}(545)$ & C/G (548) \\
\hline Median OS (months) $(95 \% \mathrm{Cl})$ & I I.3 (9.5-13.4) & $11.5(10.1-13.1)$ & $11.5(10.4-12.6)$ & $9.9(8.9-11.1)$ \\
\hline $\mathrm{HR}(95 \% \mathrm{Cl}, \mathrm{P})$ & $1.01(0.84-1.21$, & & $0.84(0.74-0.96,0.01)$ & \\
\hline Median PFS (months) $(95 \% \mathrm{Cl})$ & $5.6(5.1-6.0)$ & $5.6(4.8-5.7)$ & $5.7(5.6-6)$ & $5.5(4.8-5.6)$ \\
\hline $\mathrm{HR}(95 \% \mathrm{Cl}, P)$ & $0.96(0.80-1.16$ & & $0.85(0.74-0.98,0.02)$ & \\
\hline
\end{tabular}

Abbreviations: $\mathrm{C}$, cisplatin; $\mathrm{Cl}$, confidence interval; $\mathrm{G}$, gemcitabine; HR, hazard ratio; $\mathrm{N}$, necitumumab; NSCLC, non-small-cell lung cancer; OS, overall survival; $\mathrm{P}$, pemetrexed; PFS, progression-free survival.

patients with nonsquamous histology, while the SQUIRE trial enrolled those with squamous cell carcinoma. ${ }^{33,34}$

INSPIRE was an open-label, randomized, multicenter study that enrolled patients with metastatic lung cancer with nonsquamous histology. Patients were randomized in a $1: 1$ ratio to receive $75 \mathrm{mg} / \mathrm{m}^{2}$ of cisplatin and $500 \mathrm{mg} / \mathrm{m}^{2}$ of pemetrexed with or without $800 \mathrm{mg}$ of necitumumab intravenous on days 1 and 8 . Treatment was for six cycles, and necitumumab was continued until disease progression or unacceptable toxicity. The primary end point was OS. The study was prematurely stopped when an independent data safety monitoring committee found more fatal thromboembolic episodes on the necitumumab study arm. There were a total of $8 \%$ grade 3 or higher venous thromboembolic episodes in the experimental arm vs $4 \%$ with chemotherapy alone. In general, there were more toxicities and deaths with necitumumab treatment. With 633 patients enrolled, there was no difference in the median OS between the experimental arm (11.3 months, 95\% CI: 9.5-13.4) and the control arm (11.5 months, 95\% CI: 0.84-1.21).

The SQUIRE trial was an open-label, randomized, multicenter study conducted in 26 countries. The enrolled patients had metastatic squamous cell lung cancer and were chemotherapy naive. They were randomized $1: 1$ to receive $75 \mathrm{mg} / \mathrm{m}^{2}$ of cisplatin on day $1,1250 \mathrm{mg} / \mathrm{m}^{2}$ of gemcitabine on days 1 and 8 with or without $800 \mathrm{mg}$ of necitumumab also on days 1 and 8 . The treatment was for six cycles, but in the experimental arm, necitumumab was continued until disease progression or intolerable side effects. Primary end point of this study was OS with secondary end points being PFS, objective response rate, time to treatment failure, and safety. A total of 1093 patients were enrolled over 2 years with 545 in experimental arm and 548 in the standard treatment arm. The median follow-up was 25.2 and 24.8 months, respectively. The patient characteristics were well balanced with ${ }^{3} 90 \%$ smokers in both arms. OS was statistically significant in the experimental arm at 11.5 months when compared to the chemotherapy-alone arm at 9.9 months ( $\mathrm{HR}=0.84,95 \%$
CI: $0.74-0.96, P=0.01)$. PFS was also statistically significant favoring the necitumumab arm 5.7 vs 5.5 months $(\mathrm{HR}=0.84$, 95\% CI: $0.75-0.95, P=0.006)$. The overall response rate was $31.2 \%$ in the necitumumab arm vs $28.8 \%$ in the control, and this difference was not statistically significant $(P=0.40)$. More patients $(72 \%)$ in the necitumumab arm experienced at least one grade 3 or higher toxicity compared to controls (62\%). Hypomagnesemia was higher with necitumumab therapy ( $9 \%$ vs $1 \%$ ), and the venous thromboembolism rate was $5 \%$ vs $2.6 \%$, respectively. The overall side effect profile was acceptable and predictable in this study. Based on these data, necitumumab was approved by the US Food and Drug Administration in November 2015 for the treatment of advanced squamous cell carcinoma in combination with cisplatin and gemcitabine in the first-line setting.

\section{Biomarkers for anti-EGFR antibody therapy}

Tumor EGFR expression has been studied as a predictor for response to the EGFR inhibitors. The EGFR expression data from the FLEX trial were analyzed as an $\mathrm{H}$ score using immunohistochemistry. ${ }^{35}$ A score from 0 to 300 was assigned and 200 was taken as a discriminatory threshold. It was noted that patients with high $\mathrm{H}\left({ }^{3} 200\right)$ scores had longer OS with the addition of cetuximab to chemotherapy than with chemotherapy alone (median OS: 12 vs 9.6 months $[\mathrm{HR}=0.73,95 \% \mathrm{CI}: 0.58-0.93, P=0.011])$. No benefit was noted in those with a low score $(<200)$ with the addition of cetuximab (median OS: 9.8 vs 10.3 months [HR $=0.99,95 \%$ CI: $0.84-1.16, P=0.88])$. The Southwest Oncology Group conducted a trial, SWOG 0819 , that prospectively analyzed FISH positivity as a predictor of benefit from cetuximab. In this study, the chemotherapy backbone was cisplatin and paclitaxel with or without bevacizumab. ${ }^{36}$ Survival benefit was noted in FISH-positive patients (both adenocarcinoma and squamous) who received chemotherapy with cetuximab, although it was not statistically significant ( $\mathrm{HR}=0.83,95 \%$ CI: $0.67-1.04, P=0.1)$. However, in patients with squamous 
cell histology, the benefit was significantly greater with cetuximab (HR $=0.56,95 \% \mathrm{CI}$ : $0.37-0.84, P=0.006)$. Similarly, in the SQUIRE trial, as per a preplanned exploratory analysis, EGFR expression was taken into consideration and patients were classified as expressors (EGFR $>0$ ) or nonexpressors (EGFR $=0$ ) to assess benefit from necitumumab. ${ }^{37}$ When survival was analyzed, EGFR-expressing patients had a more favorable outcome with necitumumab $(\mathrm{HR}=0.79$, 95\% CI: $0.69-0.92, P=0.002)$ than those who were nonexpressing $(\mathrm{HR}=1.52,95 \% \mathrm{CI}: 0.74-3.12, P=0.253)$. EGFR evaluation based on FISH was also studied in a subset analysis. ${ }^{38}$ The median OS was more favorable for those patients who were EGFR FISH positive in the necitumumab arm when compared to chemotherapy alone (12.6 vs 9.2 months), but this is not statistically significant ( $\mathrm{HR}=0.70,95 \% \mathrm{CI}$ : 0.52-0.96). Although EGFR expression by both FISH and IHC does predict a trend toward benefit from the addition of necitumumab, more data need to be generated before determining the strength of this biomarker.

\section{Discussion}

Histology is one of the most important factors in deciding treatment options for NSCLC. There are a number of actionable targets that have been identified particularly for nonsquamous carcinoma, including EGFR-activating mutations and ALK and ROS1 rearrangements. VEGF inhibitors such as bevacizumab are also only approved in NSCLC. Although the PD-L1 inhibitor pembrolizumab has been approved as first line for any NSCLC histology, $\geq 50 \%$ expression of PD-L1 levels is still required. Squamous cell carcinoma has very limited options with chemotherapy as the standard choice. A platinum combination with either gemcitabine or taxane is usually utilized as the first-line treatment. As a result of this lack of progress, survival for the squamous cell lung cancer patient has not improved in quite some time.

EGFR expression is ubiquitous in NSCLC, and use of this pathway to target cancer cells has been an area of interest. Necitumumab is a second-generation human monoclonal antibody that has shown promise in the treatment of squamous cell lung cancer based on the results of the SQUIRE trial. It has received Food and Drug Administration approval in the US when used in combination with cisplatin and gemcitabine as the first-line treatment. However, necitumumab has mixed acceptability in general oncology practice. One of the major areas of concern is its cost in view of a modest survival benefit probably limiting wide spread use. A recent analysis by Goldstein et $\mathrm{al}^{39}$ attempted to provide a valuebased cost range for this agent. A possible solution to this issue would be better patient selection. A reliable biomarker could potentially determine which patients are more likely to benefit from the addition of necitumumab to chemotherapy. A retrospective analysis of the SQUIRE trial did show improvement in OS and PFS in patients who had an increased EGFR gene copy number by FISH. Although it is difficult to make a definite conclusion from this observation, it is imperative that future studies focus on identifying a predictive biomarker.

It is known that squamous cell lung cancer has a high level of mutational burden. It is speculated that EGFR monoclonal antibodies may increase EGFR-specific cytotoxic T lymphocytes and prime the immune system. ${ }^{40}$ In this regard, combining this drug with immunotherapy could also be another potential avenue.

Combining necitumumab with EGFR-TKIs is another consideration since these drugs act by different mechanisms on the same receptor. A Phase I trial is currently testing the combination of osemertinib with necitumumab in NSCLC with activating EGFR mutations (NCT02496663). Similarly, combination with a CDK4/6 inhibitor abemaciclib is also being evaluated in another Phase I trial (NCT02411591).

\section{Conclusion}

Although treatment with necitumumab has a modest clinical benefit, it does provide an option in the limited drug inventory for squamous cell NSCLC. Its combination with other agents is currently a fertile area of research that will hopefully yield better outcomes for cancer patients.

\section{Disclosure}

AJW has research support from Boehringer Ingelheim, and is a member of advisory board for Astra Zeneca, Ariad, Coherus, and Boehringer Ingelheim. MKT reports no conflicts of interest in this work.

\section{References}

1. Siegel RL, Miller KD, Jemal A. Cancer statistics, 2016. CA Cancer J Clin. 2016;66(1):7-30.

2. Sher T, Dy GK, Adjei AA. Small cell lung cancer. Mayo Clin Proc. 2008;83(3):355-367.

3. Reck M, Popat S, Reinmuth N, De Ruysscher D, Kerr KM, Peters S. Metastatic non-small-cell lung cancer (NSCLC): ESMO Clinical Practice Guidelines for diagnosis, treatment and follow-up. Ann Oncol. 2014;25(Suppl 3):iii27-iii39.

4. Molina JR, Yang P, Cassivi SD, Schild SE, Adjei AA. Non-small cell lung cancer: epidemiology, risk factors, treatment, and survivorship. Mayo Clin Proc. 2008;83(5):584-594.

5. Schiller JH, Harrington D, Belani CP, et al. Comparison of four chemotherapy regimens for advanced non-small-cell lung cancer. $N$ Engl J Med. 2002;346(2):92-98.

6. Chan BA, Hughes BG. Targeted therapy for non-small cell lung cancer: current standards and the promise of the future. Transl Lung Cancer Res. 2015;4(1):36-54.

7. Reck M, Rodríguez-Abreu D, Robinson AG, et al. Pembrolizumab versus chemotherapy for PD-L1-positive non-small-cell lung cancer N Engl J Med. 2016;375(19):1823-1833. 
8. Cancer Genome Atlas Research Network. Comprehensive genomic characterization of squamous cell lung cancers. Nature. 2012;489(7417): 519-525.

9. Rekhtman N, Paik PK, Arcila ME, et al. Clarifying the spectrum of driver oncogene mutations in biomarker-verified squamous carcinoma of lung: lack of EGFR/KRAS and presence of PIK3CA/AKT1 mutations. Clin Cancer Res. 2012;18(4):1167-1176.

10. Heist RS, Mino-Kenudson M, Sequist LV, et al. FGFR1 amplification in squamous cell carcinoma of the lung. J Thorac Oncol. 2012; 7(12):1775-1780.

11. Kris MG, Johnson BE, Berry LD, et al. Using multiplexed assays of oncogenic drivers in lung cancers to select targeted drugs. JAMA. 2014; 311(19):1998-2006.

12. Antonicelli A, Cafarotti S, Indini A, et al. EGFR-targeted therapy for non-small cell lung cancer: focus on EGFR oncogenic mutation. Int $J$ Med Sci. 2013;10(3):320-330.

13. Pirker R. Epidermal growth factor receptor-directed monoclonal antibodies in nonsmall cell lung cancer: an update. Curr Opin Oncol. 2015;27(2):87-93.

14. Zhang H, Berezov A, Wang Q, et al. ErbB receptors: from oncogenes to targeted cancer therapies. J Clin Invest. 2007;117(8):2051-2058.

15. Oda K, Matsuoka Y, Funahashi A, Kitano H. A comprehensive pathway map of epidermal growth factor receptor signaling. Mol Syst Biol. 2005;1:2005.0010.

16. Derer S, Bauer P, Lohse S, et al. Impact of epidermal growth factor receptor (EGFR) cell surface expression levels on effector mechanisms of EGFR antibodies. J Immunol. 1950;2012(189):5230-5239.

17. Rosell R, Robinet G, Szczesna A, et al. Randomized phase II study of cetuximab plus cisplatin/vinorelbine compared with cisplatin/ vinorelbine alone as first-line therapy in EGFR-expressing advanced non-small-cell lung cancer. Ann Oncol. 2008;19(2):362-369.

18. Butts CA, Bodkin D, Middleman EL, et al. Randomized phase II study of gemcitabine plus cisplatin or carboplatin [corrected], with or without cetuximab, as first-line therapy for patients with advanced or metastatic non small-cell lung cancer. J Clin Oncol. 2007;25:5777-5784.

19. Pirker R, Pereira JR, Szczesna A, et al. Cetuximab plus chemotherapy in patients with advanced non-small-cell lung cancer (FLEX): an openlabel randomised phase III trial. Lancet. 2009;373(9674):1525-1531.

20. Lynch TJ, Patel T, Dreisbach L, et al. Cetuximab and first-line taxane/ carboplatin chemotherapy in advanced non-small-cell lung cancer: results of the randomized multicenter phase III trial BMS099. J Clin Oncol. 2010;28(9674):911-917.

21. Pujol JL, Pirker R, Lynch TJ, et al. Meta-analysis of individual patient data from randomized trials of chemotherapy plus cetuximab as firstline treatment for advanced non-small cell lung cancer. Lung Cancer. 2014;83(2):211-218.

22. Li S, Kussie P, Ferguson KM. Structural basis for EGF receptor inhibition by the therapeutic antibody IMC-11F8. Structure. 2008;16(2):216-227.

23. Lu D, Zhang H, Koo H, et al. A fully human recombinant IgG-like bispecific antibody to both the epidermal growth factor receptor and the insulin-like growth factor receptor for enhanced antitumor activity. J Biol Chem. 2005;280(20):19665-19672.

24. Prewett M, Tonra JR, Rajiv B, et al. Antitumor activity of a novel, human anti-epidermal growth factor receptor (EGFR) monoclonal antibody (IMC-11F8) in human tumor xenograft models. Cancer Res. 2004;64:1235.

25. Liu M, Zhang H, Jimenez X, et al. Identification and characterization of a fully human antibody directed against epidermal growth factor receptor for cancer therapy. Cancer Res. 2004;64:163.
26. Saxena B, Sundaram ST, Walton W, et al. Differentiation between the EGFR antibodies necitumumab, cetuximab, and panitumumab: in vitro biological and binding activities. J Clin Oncol. 2011;29:e13030.

27. Patel D, Saxena B, Zhou Q, et al. Differential induction of antibodydependent cellular cytotoxicity (ADCC) against human EGFR-expressing NSCLC cell lines by necitumumab, cetuximab, and panitumumab. J Clin Oncol. 2011;29:e21075.

28. Prewett M, Bassi R, Youssoufian H, Rowinsky E, Tonra J. The fully human EGFR antibody IMC-11F8 significantly increases the antitumor effects of cisplatin + gemcitabine in human non-small cell lung cancer models. Cancer Res. 2009;69:2774.

29. Samakoglu S, Deevi DS, Li H, et al. Preclinical rationale for combining an EGFR antibody with cisplatin/gemcitabine for the treatment of NSCLC. Cancer Genomics Proteomics. 2012;9(2):77-92.

30. Kuenen B, Witteveen PO, Ruijter R, et al. A phase I pharmacologic study of necitumumab (IMC-11F8), a fully human IgG1 monoclonal antibody directed against EGFR in patients with advanced solid malignancies. Clin Cancer Res. 2010;16(6):1915-1923.

31. Nokihara H, Yamamoto N, Tamura Y, et al. O3-9-2A phase 1 study of necitumumab (anti-EGFR monoclonal antibody) in Japanese patients with advanced solid tumors. Ann Oncol. 2014;25:v70.

32. Elez E, Hendlisz A, Delaunoit T, et al. Phase II study of necitumumab plus modified FOLFOX6 as first-line treatment in patients with locally advanced or metastatic colorectal cancer. Br J Cancer. 2016;114(4):372-380.

33. Thatcher N, Hirsch FR, Luft AV, et al. Necitumumab plus gemcitabine and cisplatin versus gemcitabine and cisplatin alone as first-line therapy in patients with stage IV squamous non-small-cell lung cancer (SQUIRE): an open-label, randomised, controlled phase 3 trial. Lancet Oncol. 2015;16(7):763-774.

34. Paz-Ares L, Mezger J, Ciuleanu TE, et al. Necitumumab plus pemetrexed and cisplatin as first-line therapy in patients with stage IV non-squamous non-small-cell lung cancer (INSPIRE): an open-label, randomised, controlled phase 3 study. Lancet Oncol. 2015;16(3):328-337.

35. Pirker R, Pereira JR, von Pawel J, et al. EGFR expression as a predictor of survival for first-line chemotherapy plus cetuximab in patients with advanced non-small-cell lung cancer: analysis of data from the phase 3 FLEX study. Lancet Oncol. 2012;13(1):33-42.

36. Herbst R, Redman MW, Kim ES, et al. A randomized, phase III study comparing carboplatin/paclitaxel or carboplatin/paclitaxel/bevacizumab with or without concurrent cetuximab in patients with advanced nonsmall cell lung cancer (NSCLC): SWOG S0819. Abstract PLEN04.01. In: 16th World Conference on Lung Cancer 2015.

37. Paz-Ares L, Socinski MA, Shahidi J, et al. Correlation of EGFRexpression with safety and efficacy outcomes in SQUIRE: a randomized, multicenter, open-label, phase III study of gemcitabine-cisplatin plus necitumumab versus gemcitabine-cisplatin alone in the first-line treatment of patients with stage IV squamous non-small-cell lung cancer. Ann Oncol. 2016;27:1573-1579.

38. Hirsch FR, Boyle TA, Thatcher N, et al. EGFR IHC and FISH correlative analyses (SQUIRE trial): Necitumumab + gemcitabine-cisplatin vs gemcitabine-cisplatin in 1st-line squamous NSCLC. Abstract ORAL32.05. In:16th World Conference on Lung Cancer. Denver, CO, USA, 2015.

39. Goldstein DA, Chen Q, Ayer T, et al. Necitumumab in metastatic squamous cell lung cancer: establishing a value-based cost. JAMA Oncol. 2015;1(9):1293-1300.

40. Trivedi S, Concha-Benavente F, Srivastava RM, et al. Immune biomarkers of anti-EGFR monoclonal antibody therapy. Ann Oncol. 2015; 26(1):40-47. 


\section{Publish your work in this journal}

Lung Cancer: Targets and Therapy is an international, peer-reviewed, open access journal focusing on lung cancer research, identification of therapeutic targets and the optimal use of preventative and integrated treatment interventions to achieve improved outcomes, enhanced survival and quality of life for the cancer patient. Specific topics covered in the journal include: Epidemiology, detection and screening Cellular research and biomarkers; Identification of biotargets and agents with novel

Submit your manuscript here: https://www.dovepress.com/lung-cancer-targets--therapy-journa mechanisms of action; Optimal clinical use of existing anticancer agents, including combination therapies; Radiation and surgery; Palliative care; Patient adherence, quality of life, satisfaction; Health economic evaluations. The manuscript management system is completely online and includes a very quick and fair peer-review system. Visit http://www.dovepress.com/testimonials.php to read real quotes from published authors. 